\title{
THE MISCIBLE POOL AND TURNOVER RATE OF HYDRO- CORTISONE IN MAN
}

\author{
BY RALPH E. PETERSON AND JAMES B. WYNGAARDEN \\ (From the National Institute of Arthritis and Metabolic Diseases, National Institutes of Health, \\ United States Public Health Service, Bethesda, Md.)
}

(Submitted for publication December 9, 1955; accepted January 19, 1956)

In 1948, Mason and Sprague (1) reported the isolation of hydrocortisone from the urine of a patient with Cushing's syndrome, and thus provided evidence that hydrocortisone was produced by the human adrenal cortex. Subsequently, hydrocortisone was found to be one of the principal corticoids in human adrenal gland perfusates (2) and in human peripheral blood (3). These observations strongly suggest that hydrocortisone may be the principal corticosteroid secreted by the adrenal cortex of man. Recent studies $(4,5)$ utilizing hydrocortisone-4-C ${ }^{14}$ have elucidated much new information regarding the metabolism and physiological disposition in man of this naturally occurring adrenal steroid.

The availability of labeled hydrocortisone has made possible the direct estimation of the magnitude of the reservoir of hydrocortisone in the body, and the rate at which new, non-isotopic hydrocortisone is synthesized in the body and enters the reservoir. This report is concerned with the experimental determination of the magnitude of the miscible pool of hydrocortisone and the rate of its turnover in man. These estimations depend upon serial measurements of the specific activity of circulating hydrocortisone after the infusion of trace quantities of hydrocortisone-4-C ${ }^{14}$ and analyses of these data utilizing conventional turnover calculations $(6,7)$. Observations have been made in normal subjects, and subjects receiving adrenocorticotropin and $\Delta^{1}$ cortisone (prednisone).

\section{MATERIALS AND METHODS}

Nine normal subjects ( 7 male and 2 female) were used for these studies. Each subject received 1 to 2.5 microcuries of hydrocortisone-4-C dissolved in 2 to $5 \mathrm{ml}$. of 10 per cent ethanol in sterile distilled water. The steroid was administered intravenously in the fasting state in the morning over a period of approximately 3 minutes. Heparinized blood samples ( 40 to $60 \mathrm{ml}$. each) were collected at 30 to 40 -minute intervals after injection of the isotope.
Procedure for determination of specific activity of circulating hydrocortisone

Twenty-five to $35 \mathrm{ml}$. of plasma were extracted gently for 10 minutes on a rotator (Arthur $\mathrm{H}$. Thomas Co., Catalog No. 3623) in a 700-ml. Erlenmeyer flask with 5 volumes of dichloromethane (purified by passing through a column of silica gel [5]).

The plasma and solvent were gently transferred to a 200-ml. ground-glass stoppered cylinder, and the plasma removed by aspiration.

The dichloromethane extract was washed successively with $1 / 16$ volume of $0.01 \mathrm{~N}$ sodium hydroxide, 1/15 volume of $0.1 \mathrm{M}$ acetic acid, and $1 / 16$ volume of water.

The washed extract was evaporated to dryness in vacuo at a temperature of 30 to $40^{\circ} \mathrm{C}$.

The residue was dissolved in a small volume of dichloromethane and then applied to Whatman No. 1 filter paper (16 by $55 \mathrm{~cm}$.) previously washed continuously with reagent grade methanol for 10 or more days in a large chromatography cabinet (Chromatocab).1 The filter paper was kept in the Chromatocab until ready for use. A reference standard containing 5 to 10 micrograms of hydrocortisone was run on the same filter paper strip.

After an initial 1 to 2-hour equilibration period at room temperature in a modified Bush-type (8) system (benzene 4 : methanol 2: water 1), the chromatogram was developed for 6 to 8 hours.

Following the chromatography, the strip was removed and scanned with ultraviolet light. The hydrocortisone standard and plasma hydrocortisone were located and marked with pencil (hydrocortisone moves approximately $10 \mathrm{~cm}$. in 6 hours).

A small transverse band of paper (15 mm. wide and $30 \mathrm{~mm}$. long) containing the plasma hydrocortisone was cut out. The band was cut as narrow as possible, perpendicular to the running direction of the solvent. When the plasma hydrocortisone was present in quantities insufficient to detect with the ultraviolet light, the band was cut at a position directly opposite the hydrocortisone standard.

The hydrocortisone was eluted from the paper with 3 to $4 \mathrm{ml}$. of cold 95 per cent redistilled ethanol, and the ethanol evaporated to dryness with nitrogen.

The residue was dissolved in a small volume of purified dichloromethane $(4$ to $8 \mathrm{ml}$.). An aliquot of known

1 "Chromatocab." Research Equipment Corporation, Oakland, California. 


\section{FLLUORESCENCE SPECTRAL CHARACTERISTICS OF HYDROCORTISONE} AND PLASMA STEROID ELUTED FROM PAPER CHROMATOGRAM
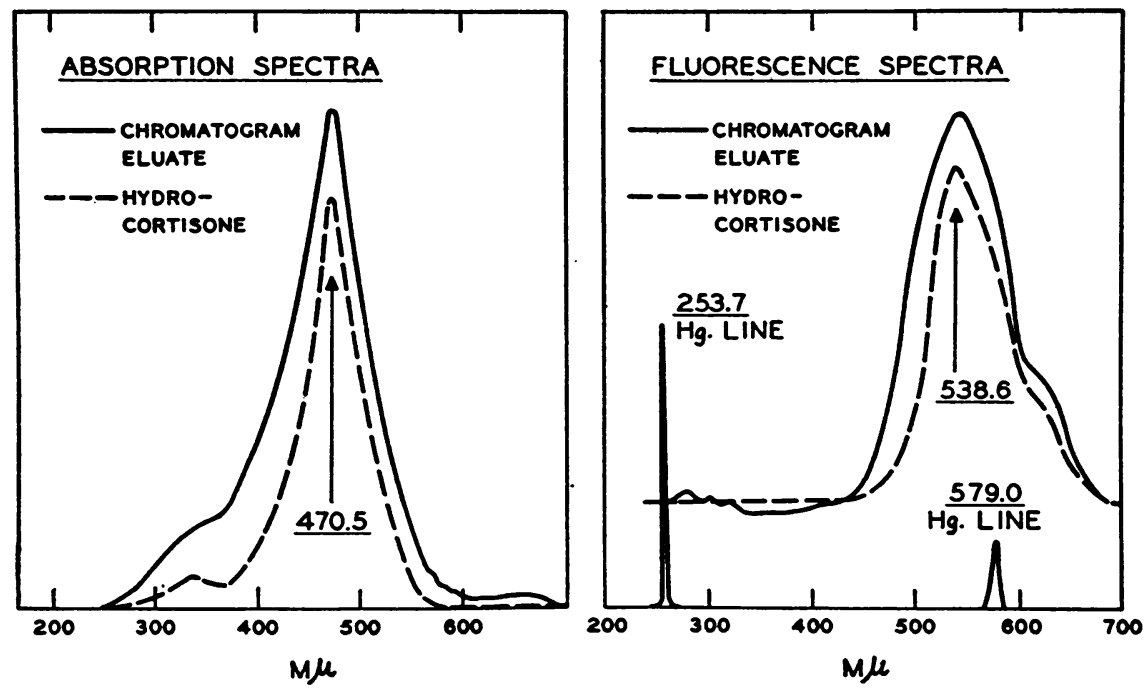

Fig. 1. Fluorescence Spectral Characteristics of Hydrocortisone and the Plasma Steroid Eluted from Paper Chromatogram

Spectra determined in mixture 7 parts $\mathrm{H}_{2} \mathrm{SO}_{4}$ and 3 parts ethanol.

volume was transferred to a small conical ground-glass stoppered tube for fluorescence assay.

An aliquot for carbon" assay was evaporated to dryness and the residue dissolved in methanol and transferred quantitatively to a stainless steel planchet (sur- face area of $1.6 \mathrm{sq}$. $\mathrm{cm}$. and depth of $0.6 \mathrm{~cm}$.), and the methanol evaporated to dryness on a rotating platform with the aid of a stream of air and an infra-red lamp. The samples were counted in a Robinson gas-flow detector (9) to within an error of approximately 3 per

\section{FLUORESCENCE CHARACTERISTICS OF HYDROCORTISONE AND PLASMA STEROID ELUTED FROM PAPER CHROMATOGRAM}

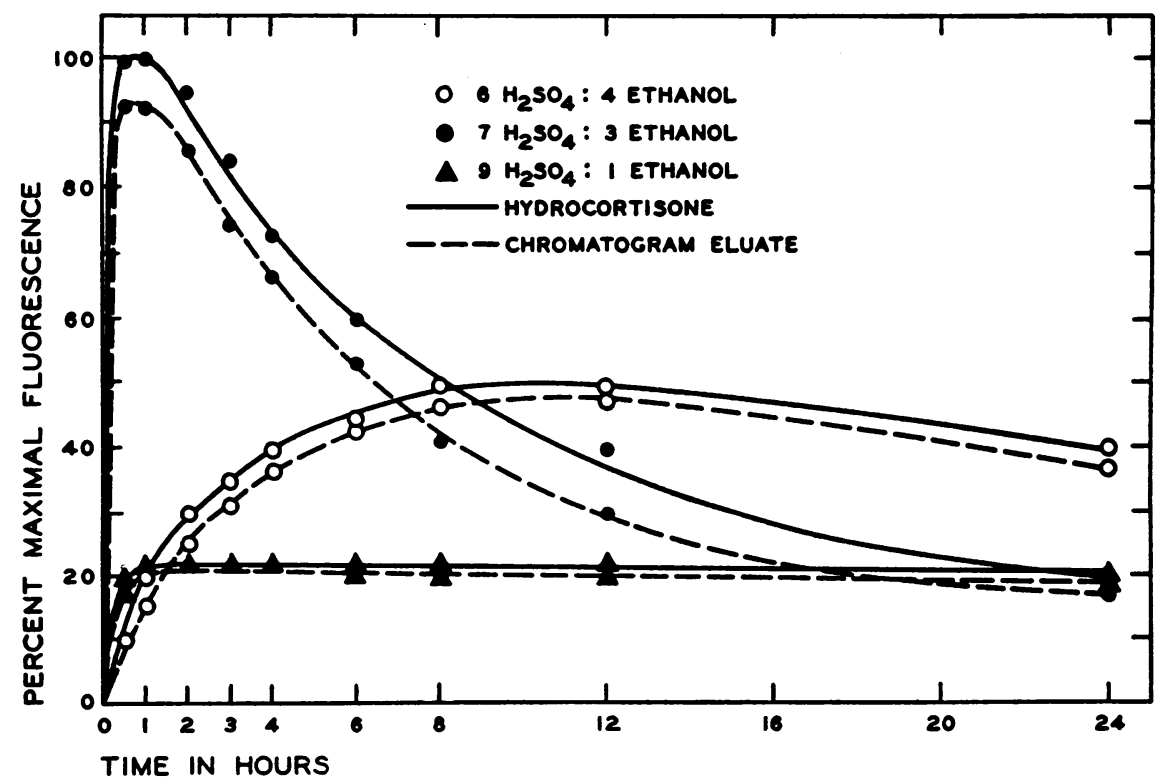

Fig. 2. Fluorescence Characteristics of Hydrocortisone and the Plasma Steroid Eluted from Paper Chromatogray 
SULFURIC ACID ABSORPTION SPECTRA OF HYDROCORTISONE AND THE PLASMA STEROID ELUTED FROM PAPER CHROMATOGRAM

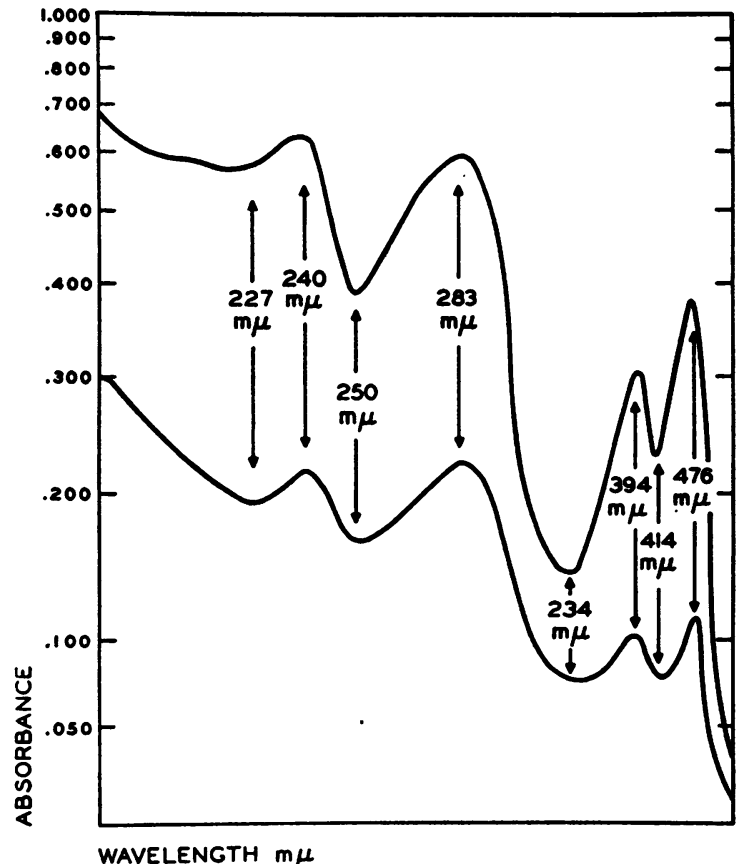

Fig. 3. Sulfuric Actd Absorption Spectra of Hydrocortisone (Upper Curve) and the Plasma Steroid Eluted from Paper Chromatogram (Lower Curve)

Steroids incubated at room temperature for 2 hours in concentrated sulfuric acid and spectra run in Beckman DK Recording Spectrophotometer.

cent. This detector connected to a Nuclear Model 172 scaler gave a background of 3 counts per minute with an efficiency for carbon ${ }^{14}$ of about 53 per cent at infinite thinness. All counting results were corrected for instrument variation by reference to a barium carbonate- $\mathrm{C}^{\mathbf{1 4}}$ standard.

The other dichloromethane aliquot was used for assay of fluorescence by a modification of the method of Sweat (10). One ml. of a reagent containing 7 parts by volume of concentrated sulfuric acid and 3 parts by volume of redistilled ethanol was added rapidly to the dichloromethane, and the steroid extracted into the acid phase by vigorous shaking, immediately. The dichloromethane (upper) layer was removed by aspiration.

After standing for 60 minutes the acid was transferred to a $1 \mathrm{~cm}$. diameter pyrex cuvette and the fluorescence measured in a Farrand fluorimeter using the following filter combinations: primary filter, $470 \mathrm{~m} \mu$ interference and No. 5133 Corning glass filter; secondary filters, 540 $\mathrm{m} \mu$ interference and No. 3486 Corning glass filter.

Standards containing $0.25,0.5$, and 0.75 micrograms of hydrocortisone were read with the unknowns. A linear relationship existed between the intensity of fluorescence and concentrations of hydrocortisone over a range of 0.01 to 2.0 micrograms. The plasma samples and hydrocortisone standards were read against a dichloromethane reagent blank. Filter paper blanks were also run, but with levels of hydrocortisone of 0.5 micrograms or more, these blanks contributed a negligible fluorescence.

The specific activity of the plasma hydrocortisone expressed as counts per minute per microgram was then calculated from the radioactivity value and the quantitative hydrocortisone value as determined by fluorescence analysis.

\section{Evaluation of Basic Assumptions Necessary for Turnover Rate Studies}

\section{1) Purity of the hydrocortisone of plasma extracts and paper chromatogram eluates}

(a) Migration rate on chromatogram-The dichloromethane extract of plasma contains a substance that migrates at the same rate as hydrocortisone, as determined with ultraviolet light scanning and alkaline blue tetrazolium staining. On addition of authentic hydrocortisone to the dichloromethane extract of plasma (mixed chromatogram), a single spot migrating at the same rate as hydrocortisone was found.

(b) Fluorescence spectra-Figure 1 shows the spectral curves of fluorescence (activating and emitting energies) of authentic hydrocortisone and of the substance eluted from paper after chromatography of a plasma dichloromethane extract. ${ }^{2}$ Figure 2 shows the fluorescence intensities of authentic hydrocortisone and the substance present in the chromatogram eluate as they vary with time in various concentrations of sulfuric acid and ethanol. The fluorescence intensity-time curves at these three concentrations of sulfuric acid appear to be characteristic for each individual steroid which fluoresces under these conditions.

(c) Sulfuric acid absorption spectra-Figure 3 shows the absorption spectra of authentic hydrocortisone in sulfuric acid, and of the substance eluated from paper after chromatography.

(d) Constancy of specific activity-Table I lists the specific activities of the steroid (hydrocortisone) in a dichloromethane extract of plasma eluted from paper after chromatography. (The plasma consisted of a pool collected from 3 normal subjects 30 minutes to 2 hours following intravenous administration of hydrocortisone4-C ${ }^{14}$.) Aliquots of the paper eluate were assayed by the

TABLE I

Specific activities of plasma hydrocortisone after elution from paper chromatogram

\begin{tabular}{lccc}
\hline \hline & \multicolumn{3}{c}{ Counts per minute/microgram } \\
\cline { 2 - 4 } & $\begin{array}{c}\text { Hydro- } \\
\text { cortisone }\end{array}$ & $\begin{array}{c}\text { Hydro- } \\
\text { cortisone } \\
\text { acetate }\end{array}$ & $\begin{array}{c}\text { Tetra- } \\
\text { hydro- } \\
\text { hydro- } \\
\text { cortisone }\end{array}$ \\
\hline $\begin{array}{lccc}\text { Fluorescence assay } \\
\text { Phenylhydrazine assay }\end{array}$ & 130 & 125 & 125 \\
\hline
\end{tabular}

2 We are indebted to Dr. Robert Bowman, of the $\mathrm{Na}$ tional Heart Institute, for the spectral studies. 
TABLE II

Partition coefficients of authentic hydrocortisone and labeled plasma hydrocortisone after elution from paper chromatogram

\begin{tabular}{|c|c|c|c|}
\hline Solvent systems & $\begin{array}{c}\mathrm{K}^{*} \\
\text { authentic } \\
\text { hydro- } \\
\text { cortisone }\end{array}$ & $\begin{array}{c}\mathbf{K} \\
\text { plasma } \\
\text { hydro- } \\
\text { cortisone }\end{array}$ & $\begin{array}{c}\text { Ratio } \\
\text { specific } \\
\text { activity } \\
\text { upper } \\
\text { and lower } \\
\text { solvent } \\
\text { phases }\end{array}$ \\
\hline $\begin{array}{l}\text { Water/ } \mathrm{CH}_{2} \mathrm{Cl}_{2}(1): \mathrm{CCl}_{4}(1) \\
\text { Water/CH} 2 \mathrm{Cl}_{2}(1): \mathrm{CCl}_{4}(4) \\
\text { Benzene/water }\end{array}$ & $\begin{array}{l}0.91 \\
5.40 \\
0.60\end{array}$ & $\begin{array}{l}0.91 \\
6.00 \\
0.66\end{array}$ & $\begin{array}{l}1.05 \\
1.08 \\
0.90\end{array}$ \\
\hline
\end{tabular}

* $\mathrm{K}=$ Partition coefficient (upper phase/lower phase).

fluorescence method, the phenylhydrazine method $(5,11)$, and by radioactive counting. In addition, aliquots of the eluted steroid were evaporated to dryness and the residue acetylated. The acetylated product was rechromatographed in the benzene-methanol-water system, eluted, and its specific activity determined. An additional aliquot was reduced enzymatically (12) to the tetrahydro derivative, rechromatographed in the benzene-methanolwater system, and the specific activity again determined. Finally, additional aliquots were taken for a study of partition coefficients (Table II). The eluted steroid was partitioned between 3 different solvent systems, and the ratios of specific activities in the 2 solvent phases determined. A deviation from a ratio of 1.0 would have constituted evidence for non-identity of the plasma steroid with hydrocortisone.

2) Steady state (Constancy of the magnitude of the rapidly exchangeable pool, and of the quantities of hydrocortisone entering and leaving this pool per unit time.)

Determinations of plasma hydrocortisone concentrations were made at the beginning and at the end of the study, and in none of these subjects did a variation in the plasma level of more than \pm 15 per cent occur. The subjects were therefore considered to be in a steady state with regard to plasma hydrocortisone concentrations, and thus also with regard to the magnitude of the miscible pool. It was therefore assumed that the rate of entry of hydrocortisone into the pool equalled the rate of its disappearance from the pool. The fact that after 20 to 30 minutes following injection of the hydrocortisone-4- $\mathrm{C}^{\mathbf{1}}$ the experimental specific activity values were distributed close to a straight line on a semilogarithmic plot vs. time (Figure 4 ) is in conformity with this assumption regarding the steady state.

\section{3) Failure of isotopic hydrocortisone to re-enter the miscible pool}

It appears likely that hydrocortisone, once removed from the circulating pool by the liver, does not again re-enter the pool as unaltered hydrocortisone. This conclusion is strongly suggested by an experiment wherein specific activities of circulating hydrocortisone, sampled simultaneously from a peripheral vein and from the hepatic vein by catheterization, were compared following intravenous administration of a trace quantity of labeled hydrocortisone (Figure 5). The specific activities of hydrocortisone obtained from both sites were similar for at least 3 hours, indicating no significant reversible concentration of hydrocortisone by the liver. Furthermore, although metabolites of hydrocortisone do appear in the bile (5), no unaltered hydrocortisone is thus excreted, so that re-entry of the steroid into the miscible pool by intestinal absorption appears excluded. Finally, the plasma protein binding of hydrocortisone (5) is readily reversible, as dialysis studies have shown, thus dismissing the consideration of inhomogeneity within the pool on this basis.

\section{4) Rapid mixing within the circulating pool}

When the specific activities of circulating hydrocortisone determined serially after the intravenous administration of hydrocortisone-4-C $\mathrm{C}^{14}$ were plotted on semilogarithmic coordinates, a rapid initial decline was observed (Figure 4). However, after 20 to 30 minutes, a single

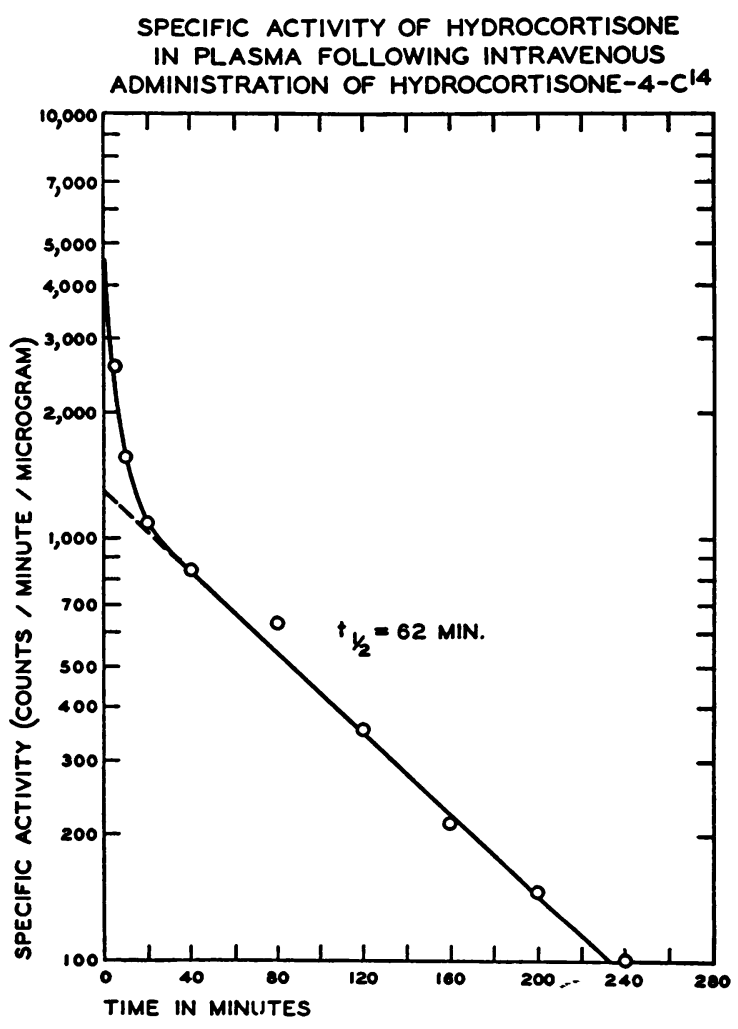

Fig. 4. Specific Activity of Hydrocortisone in Plasma Following Intravenous Administration of HYDROCORTISONE-4-C ${ }^{16}$

The data of this experiment (Subject J. B., Table III), when analyzed by the method of least squares, indicated a miscible pool of $1.052 \pm 0.100 \mathrm{mg}$. and a turnover rate of $0.709 \pm 0.087 \mathrm{mg}$. per hour. 
SPECIFIC ACTIVITY OF HYDROCORTISONE IN PERIPHERAL AND HEPATIC VEIN FOLLOWING INTRAVENOUS ADMINISTRATION OF HYDROCORTISONE-4-C 14

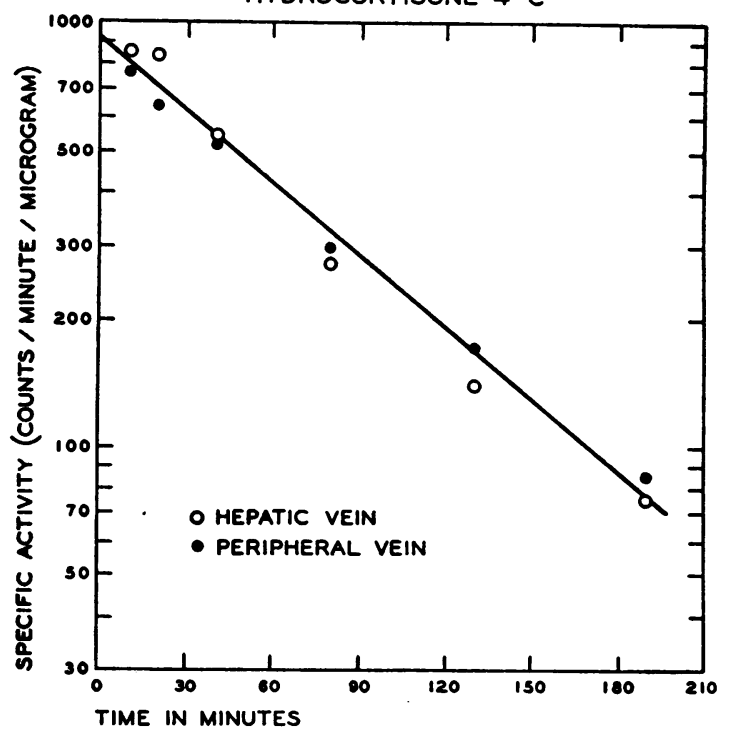

Fig. 5. Speciftc Actrvity of Hydrocortisone in Prripheral and Hepatic Vein Blood Following Intravenous Administration of Hydrocortisone-4-C ${ }^{4}$

exponential process was observed for as long as significant quantities of radioactivity were present in the plasma (4 to 6 hours). The initial rapid decline was attributed to distribution of the labeled steroid in the exchangeable hydrocortisone pool. These results suggest that equilibration of labeled hydrocortisone and circulating hydrocortisone occurred within 20 to 30 minutes.

\section{5) Trace quantity of injected hydrocortisone}

In most cases a quantity of hydrocortisone-4-C $\mathrm{C}^{44}$ equal to 10 to 25 per cent of the total body pool was injected, a quantity considered to satisfy the criteria of a trace dose.

\section{6) Purity of injected hydrocortisone-4- $C^{14}$}

The labeled hydrocortisone has been evaluated by both paper chromatography and isotope dilution and has been found to be approximately 94 per cent authentic hydrocortisone. An average figure of 94 per cent purity has been used in the calculations, which requires a knowledge of the exact quantity of hydrocortisone injected. The specific activity of this hydrocortisone was 4600 counts per minute per microgram.

\section{RESULTS}

After the injection of hydrocortisone-4-C ${ }^{14}$, a rapid initial fall in specific activity was observed (Figure 4). After approximately 20 minutes, a more gradual decline occurred. This gradual de- cline represented a first order function, since a semilogarithmic plot revealed that these points approximated a straight line. This exponential decay was interpreted as a measure of the rate of replacement of the labeled hydrocortisone by newly synthesized unlabeled hydrocortisone.

By extrapolation of the linear portion of the curve of specific activity to zero time, it was possible to determine the specific activity of the hydrocortisone in the body (miscible pool) capable of prompt mixing, immediately after injection (6). From this value $\left(I_{0}\right)$, and knowledge of the quantity (a) and specific activity $\left(I_{1}\right)$ of the injected tracer, the magnitude of the miscible pool (A) was calculated.

$$
A=a\left(\frac{I_{i}}{I_{0}}-1\right)
$$

The biological half-time of the hydrocortisone was obtained graphically from the linear plot of the slow component. ${ }^{3}$ The negative slope of the line gave the turnover rate expressed in pools per unit time, which was computed from the following expression (7):

$$
\text { Turnover rate }(K)=\frac{\log 2}{t_{3}}
$$

This expression is derived from the equation for a first order reaction :

where

$$
\mathrm{I}=\mathrm{I}_{\mathrm{o}} \mathrm{e}^{-\mathbf{K} \mathbf{t}}
$$

$\mathrm{I}=$ hydrocortisone-4-C $\mathrm{C}^{14}$ at any time

$\mathrm{I}_{\mathrm{o}}=$ hydrocortisone-4-C $\mathrm{C}^{14}$ at zero time

$\mathrm{t}=$ time in hours

$\mathrm{K}=$ fraction of all the hydrocortisone in the miscible pool which is replaced by nonisotopic hydrocortisone each hour.

Hydrocortisone turnover (KA), expressed in micrograms per hour, was computed from the value for the miscible pool (A) and the rate of its turnover $(\mathrm{K})$ in pools per hour. This figure was projected to mg. turned over per day by multiplying by 24 and dividing by 1000 .

8 This biological half-time must not be confused with the previously reported biological half-time for the rate of disappearance of hydrocortisone from plasma (5). The decline in specific activity is a measure of the rate of appearance of newly synthesized unlabeled hydrocortisone into the pool, and is in no way related to the rate of disappearance of hydrocortisone from the pool. 
TABLE III

Miscible pool of hydrocortisone and its turnover in normal subjects

\begin{tabular}{|c|c|c|c|c|c|c|c|c|c|c|c|c|c|}
\hline \multirow[b]{2}{*}{ Subject } & \multirow[b]{2}{*}{ Age } & \multirow{2}{*}{$\begin{array}{c}\text { Wt. } \\
\text { kilos } \\
\text { (W) }\end{array}$} & \multirow{2}{*}{$\begin{array}{c}\text { Dose } \\
\text { injected } \\
\text { (a) }\end{array}$} & \multirow{2}{*}{$\begin{array}{c}\text { Inter- } \\
\text { cept } \\
\text { (I0) }\end{array}$} & \multirow{2}{*}{$\begin{array}{c}\text { Miscible } \\
\text { pool } \\
\text { (A) }\end{array}$} & \multirow[b]{2}{*}{$t$} & \multicolumn{3}{|c|}{ Turnover } & \multirow{2}{*}{$\begin{array}{l}\text { Urinary } \\
\text { corti- } \\
\text { coids } \\
\text { (U) }\end{array}$} & \multirow{2}{*}{$\begin{array}{l}\text { Hydro- } \\
\text { cortisone } \\
\text { turn- } \\
\text { over as } \\
\text { urinary } \\
\text { corti- } \\
\text { coids }\end{array}$} & \multirow{2}{*}{$\begin{array}{c}\text { Plasma } \\
\text { hydro- } \\
\text { corti- } \\
\text { sone } \\
\text { (P) }\end{array}$} & \multirow{2}{*}{$\begin{array}{c}\text { Volume } \\
\text { of distri- } \\
\text { bution } \\
{\left[A\left(\mu g_{0}\right) /\right.} \\
10 P]\end{array}$} \\
\hline & & & & & & & (K) & (KA) & $\underset{24)}{(\mathrm{KA} X}$ & & & & \\
\hline $\begin{array}{l}\text { T. R. } \\
\text { T. R.* } \\
\text { J. W. } \\
\text { R. T. } \\
\text { R. T.* } \\
\text { E. H. } \\
\text { E. H.* } \\
\text { E. P. }{ }^{*} \\
\text { L. C. } \\
\text { J. B. } \\
\text { W. R. } \\
\text { D. B. } \\
\text { D. B.t }\end{array}$ & $\begin{array}{l}70 \\
70 \\
30 \\
16 \\
16 \\
16 \\
16 \\
20 \\
23 \\
22 \\
22 \\
26 \\
26\end{array}$ & $\begin{array}{l}70 \\
70 \\
73 \\
68 \\
68 \\
67 \\
67 \\
67 \\
66 \\
69 \\
69 \\
84 \\
84\end{array}$ & $\begin{array}{l}\mu \xi . \\
500 \\
500 \\
500 \\
500 \\
350 \\
500 \\
350 \\
300 \\
300 \\
450 \\
400 \\
270 \\
270\end{array}$ & $\begin{array}{r}c p m / \mu g . \\
860 \\
800 \\
1,200 \\
1,300 \\
820 \\
930 \\
700 \\
520 \\
920 \\
1,350 \\
990 \\
460 \\
1,400\end{array}$ & $\begin{array}{l}m g . \\
2.2 \\
2.4 \\
1.4 \\
1.8 \\
1.6 \\
2.0 \\
2.0 \\
2.4 \\
1.2 \\
1.1 \\
1.5 \\
2.4 \\
0.6\end{array}$ & $\begin{array}{l}\text { hours } \\
1.83 \\
1.53 \\
1.23 \\
1.33 \\
1.03 \\
1.43 \\
1.38 \\
2.30 \\
1.08 \\
1.03 \\
1.33 \\
1.30 \\
0.83\end{array}$ & $\begin{array}{c}\begin{array}{c}\text { Pooly } \\
\text { hr. }\end{array} \\
0.38 \\
0.45 \\
0.56 \\
0.52 \\
0.67 \\
0.49 \\
0.50 \\
0.30 \\
0.64 \\
0.67 \\
0.52 \\
0.50 \\
0.84\end{array}$ & $\begin{array}{c}\text { mg.l } \\
h r . \\
0.83 \\
1.08 \\
0.80 \\
0.92 \\
1.09 \\
0.96 \\
0.98 \\
0.70 \\
0.77 \\
0.74 \\
0.75 \\
1.22 \\
0.51\end{array}$ & $\begin{array}{c}m g . / \\
\text { day } \\
20 \\
26 \\
19 \\
22 \\
26 \\
23 \\
24 \\
17 \\
19 \\
18 \\
18 \\
29 \\
12\end{array}$ & $\begin{array}{c}\text { mg.l } \\
\text { day } \\
4.8 \\
4.8 \\
\\
5.2 \\
5.0 \\
4.3 \\
4.8 \\
4.0 \\
5.0 \\
7.0 \\
6.5 \\
10.5\end{array}$ & $\begin{array}{c}\%(U / K A \\
\times 224) \\
24.0 \\
18.5 \\
\\
23.5 \\
19.0 \\
19.0 \\
20.0 \\
23.5 \\
26.0 \\
39.0 \\
36.0 \\
38.0\end{array}$ & $\begin{array}{c}\text { Mg. \% } \\
16 \\
18 \\
11 \\
19 \\
19 \\
16 \\
16 \\
24 \\
15 \\
13 \\
17 \\
14 \\
4\end{array}$ & $\begin{array}{c}\text { liters } \\
14 \\
13 \\
11 \\
9.5 \\
8.5 \\
12 \\
12 \\
10 \\
8.0 \\
8.5 \\
8.5 \\
17 \\
15\end{array}$ \\
\hline
\end{tabular}

* The second experiments were done approximately 2 weeks following the first experiment.

+ Women.

$\ddagger$ The second study was started at 9:00 p.m.

Determined by method of Peterson and his co-workers $(5,11)$.

In order to evaluate the precision of the graphic determinations of the intercept, $I_{0}$, and of the rate constant, $K$, these values were also determined in several studies by the method of least squares. The probable error of pool size, $\pm \Delta A$, was determined by calculations previously published (13) and that of the rate constant, $\pm \Delta K$, by the method of least squares. The hydrocortisone pool size and daily turnover rate values determined by these two procedures agreed in all cases within 5 per cent, so that the graphic method of analysis was chosen for routine use.

In Table III are listed the data obtained in 9 normal subjects. The mean value for the miscible pool of hydrocortisone was $1.8 \mathrm{mg}$., with a range of 1.1 to $2.4 \mathrm{mg}$. The mean half-time of the hydrocortisone was 1.38 hours with a range of 1.03 to 2.30 hours. The mean hydrocortisone turn-

TABLE IV

Miscible pool of hydrocortisone and its turnover afler suppression and stimulation of the adrenal

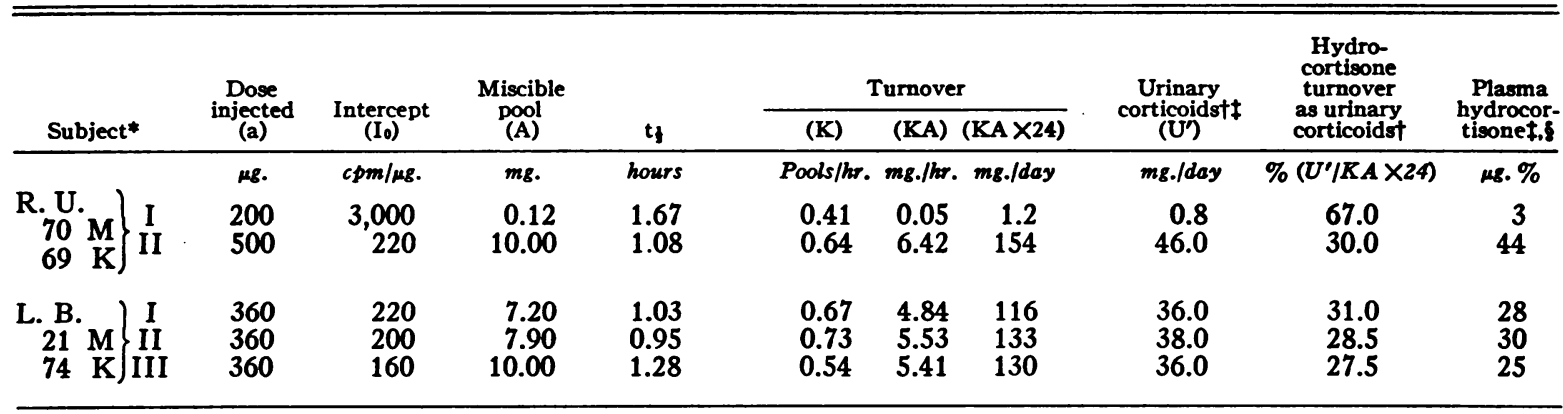

* R. U. (I) 8 hours after oral administration of $60 \mathrm{mg}$. prednisone over previous period of 42 hours.

R. U. (II) 6 hours after start of continuous infusion of 5 units adrenocorticotropin per hour.

L. B. 6 hours (I), 18 hours (II), and 40 hours (III) after start of continuous infusion of 5 units adrenocorticotropin per hour.

t Urinary excretion based on 2-hour urinary excretion at 6 to 8 hours (R. U. II ; L. B. I), 18 to 20 hours (L. B. II), and 40 to 42 hours (L. B. III).

Determined by method of Peterson and his co-workers $(5,11)$.

Mean plasma steroid value based on average of 6 different determinations made throughout the 3-hour period of the study. 
over rate was 0.52 pool per hour, or $0.91 \mathrm{mg}$. per hour with a range of 0.70 to $1.22 \mathrm{mg}$. per hour.

In two of three subjects in whom a second experiment was performed some weeks after the first, moderate variations were found in both pool size and turnover rate. Whether these differences represent experimental errors or variations in the rate of production of hydrocortisone in these subjects is uncertain. However, in one subject (D. B.) turnover studies conducted at 9:00 a.m. and at 9:00 p.m. (four days later) revealed clearly that hydrocortisone production diminished late in the evening compared with the morning. In this subject the hydrocortisone pool was $2.4 \mathrm{mg}$. at 9:00 a.m. and 0.6 mg. at 9:00 p.m. Corresponding plasma hydrocortisone concentrations were 14 and 4 micrograms per cent. Hydrocortisone production was estimated to be $1.22 \mathrm{mg}$. per hour in the morning and $0.51 \mathrm{mg}$. per hour in the late evening.

In Table IV are listed the turnover rate data in two normal male subjects obtained after the continuous intravenous administration of 5 units of adrenocorticotropin per hour over periods of 10 hours (R. U.) and 44 hours (L. B.). In R. U. the turnover study was started 6 hours after the beginning of the infusion and in case $\mathrm{L}$. $\mathrm{B}$. turnover studies were started at 6,18 , and 40 hours. Hydrocortisone pool sizes ranging from 7.2 to $10.0 \mathrm{mg}$. were found, and hydrocortisone production values equivalent to 116 to $154 \mathrm{mg}$. per day were calculated. In patient R. U., a turnover study was also done after the suppression of adrenal activity with orally administered $\Delta^{1}$ cortisone (prednisone) (10 mg. every 6 hours-first dose given 42 hours before start of study and turnover study started 8 hours after last dose). Endogenous hydrocortisone production was reduced to a rate of $1.2 \mathrm{mg}$. per day.

As an adjunct to the above results, estimations were made of the apparent volumes of distribution of the hydrocortisone pool. These were obtained by dividing the size of the pool in micrograms by the concentration of hydrocortisone in plasma in micrograms per $\mathrm{ml}$. (The method used for the determination of plasma hydrocortisone has been shown to be specific for hydrocortisone [11].) Values of 8 to 17 liters were obtained for the apparent volume of distribution of hydrocortisone.

\section{DISCUSSION}

Implicit in all isotopic turnover studies are certain assumptions, the validity of which must be evaluated in each case. An important consideration is that hydrocortisone only is being measured, and that in the determination of radioactivity only that radioactivity is measured that is due to unchanged hydrocortisone. The method described by Peterson and his co-workers $(5,11)$ has been shown to be specific for hydrocortisone normally present in plasma dichloromethane extracts, and this method would therefore be adequate for determining the hydrocortisone concentrations in plasma. However, a direct dichloromethane extract of plasma samples drawn after the infusion of hydrocortisone-4-C $\mathrm{C}^{14}$ contains many free steroids that are radioactive but are not hydrocortisone. These metabolites may account for up to 50 per cent of the radioactivity in the dichloromethane extracts of plasma (5). Data are presented to show that the steroid eluted from paper and measured fluorometrically is indeed hydrocortisone4- ${ }^{14}$. It may be of interest to note that the methods of analysis used do not depend upon obtaining quantitative recoveries from either the plasma extractions or the paper chromatography.

Another fundamental assumption is that the subject is in a steady state throughout the duration of the study, i.e., that the total quantity of the compound whose turnover is being measured is sensibly constant, and therefore that the rate of addition of newly formed compound to the miscible pool is balanced by a similar rate of removal of compound from this pool. Further, it is assumed that mixing of the fraction added within the pool is rapid with respect to the frequency of sampling, and therefore that the samples withdrawn faithfully reflect the characteristics of the entire pool.

The validity of these assumptions has been carefully examined in the present study. As was pointed out, the level of phenylhydrazine reactive material extracted from plasma was essentially constant during the 3-hour period of study in all subjects tested. Other studies have demonstrated that this plasma component consists very predominantly of hydrocortisone $(5,11)$, so that the existence of a steady state during the short period of study may logically be inferred. It must be pointed out, however, that diurnal variations in 
plasma hydrocortisone levels (14) and in urinary corticoid excretion (15) do occur, and indeed were demonstrated in some subjects of the present study. Such variations, when noted, indicated maximal adrenal activity during mid-morning hours, relative stability during the forenoon, a gradual decline in activity throughout the afternoon and evening, and minimal adrenal activity in the late evening and early morning hours. In one subject studied both in the mid-morning and late evening, a rather striking reduction in the rate of synthesis of hydrocortisone in the late evening hours was demonstrated. Since, with this one exception, the turnover studies reported in this paper were conducted in the forenoon hours, after the period of accelerated adrenal activity and before the period of tapering decline, it appears likely that these measurements of hydrocortisone turnover not only reflect steady state conditions but also constitute adrenal cortical secretion values which may be considered representative samplings of the average cortical activity of the entire day. For these reasons it appears valid to express hydrocortisone turnover in terms of daily production, even though the results were derived from a short sampling period.

In the normal individuals, the miscible pool of hydrocortisone averaged $1.8 \mathrm{mg}$., with a range of 1.1 to $2.4 \mathrm{mg}$. Approximately one-half this pool was replaced by newly synthesized hydrocortisone each hour during the period of the study. In these subjects the projected daily turnover of hydrocortisone averaged $22 \mathrm{mg}$., with a range of 17 to $29 \mathrm{mg}$.

The direct measurement of hydrocortisone production, as reported herein, has yielded values which confirm various estimates based on indirect methods, and in so doing establish the general validity of these approaches. For example, Dorfman (16) estimated hydrocortisone production to be $21 \mathrm{mg}$. per day, on the basis of the quantities of 11 oxy- and 11 desoxy-C ${ }^{10}$ neutral 17-ketosteroids in normal urine. Silber (17) also estimated daily production to $21 \mathrm{mg}$. per day, as judged from the quantity of endogenously produced phenylhydrazine chromogenes in urine, the calculations in each patient being based on the fraction of a test dose of cortisone excreted as similarly reactive metabolites. Bondy and Altrock (18) also arrived at a value of $21 \mathrm{mg}$. per day on the basis of renal vein catheterization studies. However, the apparent agreement of this value may be fortuitous since the plasma hydrocortisone method employed gave low values in normals, and the stress of the procedure might have been expected to alter adrenal activity. ${ }^{4}$ Finally, clinical experience in Addisonian and adrenalectomized patients also indicates that hydrocortisone production in healthy individuals during average activity is in the range of 25 to $35 \mathrm{mg}$. per day (19). Of course, a patient with total adrenal insufficiency is also deficient in other cortical steroids such as corticosterone, aldosterone, and various $\mathrm{C}^{19}$ steroids, and the absence of these steroids may influence the maintenance requirements of hydrocortisone.

The method reported in this paper has provided the first direct information on the extent of the maximal adrenal response in normal subjects to the continuous intravenous administration of adrenocorticotropin. It has also demonstrated that after about 6 hours the adrenal response is maximal and that hydrocortisone synthesis does not increase during the next 36 hours despite continued administration of adrenocorticotropin. These results are in agreement with our data and the data of others on the plasma hydrocortisone and urine phenylhydrazine reacting steroid levels, after adrenocorticotropin stimulation. The plasma hydrocortisone concentrations reach a constant level after 4 to 6 hours in normals. Also, after 6 to 8 hours the urinary steroid excretion per 2hour period remains constant for at least 44 hours.

After administration of a small quantity of prednisone, over a short period of time, a very marked suppression of adrenal hydrocortisone secretion results, thus demonstrating the great dependence of the adrenal for pituitary adrenocorticotropin. After this marked and rapid suppression, the adrenal in this normal subject was, however, capable of responding at a normal rate to exogenous intravenous adrenocorticotropin.

Previous studies (5) on the metabolic fate and physiological disposition of hydrocortisone have demonstrated that approximately 90 per cent of the radio-metabolites of either a tracer or a larger intravenous dose of this hormone are excreted in

\footnotetext{
4 In the study conducted during hepatic catheterization, a projected hydrocortisone turnover of $40 \mathrm{mg}$. was found, and this high value in a normal subject was regarded as a manifestation of stress.
} 
the urine. Less than one per cent of this quantity consists of unaltered hydrocortisone. After $\beta$-glucuronidase hydrolysis of conjugated metabolites, 20 to 30 per cent of the administered dose is recovered as phenylhydrazine reactive products, whereas 60 to 70 per cent of the administered dose is recovered by radioactive assay. The phenylhydrazine reactive group was discussed in terms of metabolites having reduced $\Delta_{4}, 3$-keto groups, and the latter in terms of similarly reduced steroids having in addition $\alpha$ or $\beta$-20-ol groups (5), so as no longer to react with phenylhydrazine. These recent studies show clearly the reason for the great disparity between the values for hydrocortisone turnover (Table III, Column 10) and for urinary corticoids (Table III, Column 11) as shown in this paper. The lack of a very consistent relationship between the two values (see Table III, Column 12) illustrates the hazard of placing too great emphasis on urinary corticoid values as an accurate index of adrenal cortical function.

A similar caution may be interjected with reference to the level of hydrocortisone in plasma, particularly at rather low levels which may be compatible with turnover values well within the normal range. In addition, the plasma level is often normal in the presence of either increased or decreased adrenal hydrocortisone production. In cirrhosis, for example, plasma steroid levels are normal whereas urinary corticoids are low (20), and infused hydrocortisone disappears at a rate slower than normal (5). The hydrocortisone pool is normal (in the absence of ascites) but its turnover may be decidedly reduced (20). Again in thyrotoxicosis, plasma hydrocortisone levels are normal or low, urinary corticoids are normal or increased, and infused hydrocortisone disappears at a rate faster than normal (20). In this condition, the hydrocortisone pool is normal or low but its turnover is markedly increased. Similar studies in myxedema have disclosed a reduced turnover, in the presence of normal plasma steroid levels.

The apparent volume of distribution of the miscible pool of hydrocortisone has been determined in each patient of this study. The mean value averaged 11 liters with a range of 8 to 17 liters. It is unlikely that the volume has any physical reality, since protein binding in the extravascular spaces is probably not quantitatively identical with that in plasma, where 75 per cent of hydrocortisone exists in association with non-diffusible elements (5). This volume must therefore be regarded solely as that theoretical volume in which the miscible hydrocortisone exists at a concentration equal to that of plasma.

\section{SUMMARY}

Utilizing trace quantities of intravenously administered hydrocortisone-4-C $\mathrm{C}^{14}$, we have determined the magnitude of the miscible pool of hydrocortisone in the normal subject to be 1.1 to 2.4 mg. This pool of hydrocortisone has been found to be distributed in an apparent volume of 8 to 17 liters.

Calculations of turnover rate of endogenously synthesized hydrocortisone have ranged from 17 to $29 \mathrm{mg}$. per day in 9 normal subjects.

Following maximal adrenocorticotropin stimulation, the miscible pool of hydrocortisone increased to $10 \mathrm{mg}$., and the turnover rate increased to 154 mg. per day in the normal subject. Following oral administration of $\Delta^{1}$ cortisone (prednisone), a marked decrease in both pool size and hydrocortisone turnover rate was demonstrated.

The miscible pool and turnover rate of hydrocortisone has been found to show a diurnal variation.

\section{ACKNOWLEDGMENT}

We are indebted to Mr. Charles Pierce, Miss Margaret Bollier, and Miss Aurora Karrer for valuable technical assistance.

\section{REFERENCES}

1. Mason, H. L., and Sprague, R. G., Isolation of 17hydroxycorticosterone from the urine in a case of Cushing's syndrome associated with severe diabetes mellitus. J. Biol. Chem., 1948, 175, 451.

2. Romanoff, E. B., Hudson, P., and Pincus, G., Isolation of hydrocortisone and corticosterone from human adrenal vein blood. J. Clin. Endocrinol. \& Metab., 1953, 13, 1546.

3. Bush, I. E., and Sandberg, A. A., Adrenocortical hormones in human plasma. J. Biol. Chem., 1953, 205, 783.

4. Hellman, L., Bradlow, H. L., Adesman, J., Fukushima, D. K., Kulp, J. L., and Gallagher, T. F., The fate of hydrocortisone-4-C ${ }^{24}$ in man. J. Clin. Invest., 1954, 33, 1106.

5. Peterson, R. E., Wyngaarden, J. B., Guerra, S. L., Brodie, B. B., and Bunim, J. J., The physiological disposition and metabolic fate of hydrocortisone in man. J. Clin. Invest., 1955, 34, 1779. 
6. Benedict, J. D., Forsham, P. H., and Stetten, D., Jr., The metabolism of uric acid in the normal and gouty human studied with the aid of isotopic uric acid. J. Biol. Chem., 1949, 181, 183.

7. Solomon, A. K., Equations for tracer experiments. J. Clin. Invest., 1949, 28, 1297.

8. Bush, I. E., Methods of paper chromatography of steroids applicable to the study of steroids in mammalian blood and tissues. Biochem. J., 1952, 50, 370.

9. Robinson, C. V., Windowless, flow type, proportional counter for counting $C^{14}$. Science, 1950, 112, 198.

10. Sweat, M. L., Sulfuric acid-induced fluorescence of corticosteroids. Anal. Chem., 1954, 26, 773.

11. Peterson, R. E., Karrer, A., and Guerra, S. L., Evaluation of a modified Silber-Porter procedure for the determination of plasma hydrocortisone. In preparation.

12. Tomkins, G., and Isselbacher, K. J., Enzymatic reduction of cortisone. J. Am. Chem. Soc., 1954, 76, 3100.

13. Wyngaarden, J. B., and Stetten, D., Jr., Uricolysis in normal man. J. Biol. Chem., 1953, 203, 9.

14. Migeon, C. J., Tyler, F. H., Mahoney, J. P., Florentin, A. A., Castle, H., Bliss, E. L., and Samuels,
L. T., The diurnal variation of plasma levels and urinary excretion of 17-hydroxycorticosteroids in normal subjects, night workers and blind subjects. J. Clin. Endocrinol., In press.

15. Sandberg, A. A., Nelson, D. H., Glenn, E. M., Tyler, F. H., and Samuels, L. T., 17-Hydroxycorticosteroids and 17-ketosteroids in urine of human subjects : Clinical application of a method employing $\beta$-glucuronidase hydrolysis. J. Clin. Endocrinol. \& Metab., 1953, 13, 1445.

16. Dorfman, R. I., Neutral steroid hormone metabolites. Recent Progress in Hormone Research, 1954, 9, 5.

17. Silber, R. H., Estimation of hydrocortisone secretion. Method of calculation from urinary-excretion data. Clin. Chemist., 1955, 1, 234.

18. Bondy, P. K., and Altrock, J. R., Estimation of the rate of release of adrenal 17-hydroxycorticosteroids in the human being by the venous catheter technique with a method for determining plasma 17hydroxycorticosteroids. J. Clin. Invest., 1953, 32, 703.

19. Knowlton, A. I., The modern treatment of Addison's disease. M. Clin. North America, 1952, May, 721.

20. Peterson, R. E., Unpublished data. 